\title{
Recorregut de recerca geològica i geoambiental per la comarca de l'Anoia: des de Sant Genís a Igualada, Clariana, Argençola, Carbassí i a la Panadella
}

Josep Maria Mata-Perelló

Joaquim Sanz Balagué

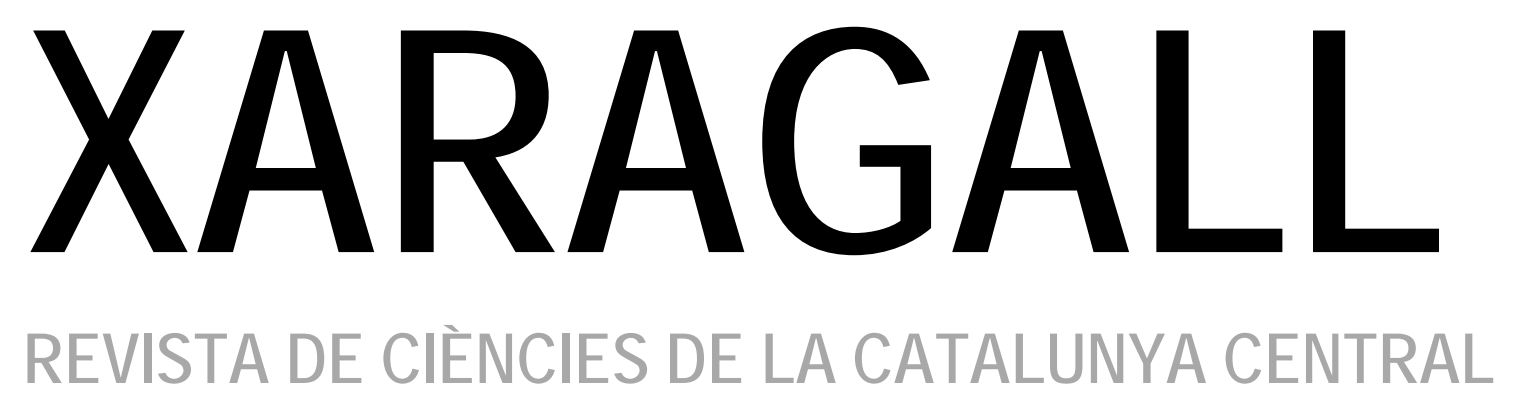

\section{n. 11}

NOVEMBRE 2014 


\section{RECORREGUT DE RECERCA GEOLÒGICA I GEOAMBIENTAL PER LA COMARCA DE L'ANOIA: DES DE SANT GENÍS A IGUALADA, CLARIANA, ARGENÇOLA, CARBASSÍ I A LA PANADELLA}

\section{Josep Maria Mata-Perelló}

Museu de geologia Valentí Masachs, Escola Politècnica Superior d'Enginyeria de Manresa (EPSEM), Universitat Politècnica de Catalunya · BarcelonaTech (UPC), 08272 Manresa, Spain

\section{Joaquim Sanz Balagué}

Departament d'Enginyeria Minera i Recursos Naturals (EMRN), Escola Politècnica Superior d'Enginyeria de Manresa (EPSEM), Universitat Politècnica de Catalunya - BarcelonaTech (UPC), 08272 Manresa, Spain

Paraules clau: Depressió Geològica de l'Ebre, materials terciaris, materials quaternaris, Patrimoni miner

\section{Resum}

Itinerari realitzat el 12 de gener de 2014. En aquesta ocasió, es realitzarà un recorregut geològic a través de diferents indrets de la Depressió Geològica de I’Ebre; i més concretament pels sectors corresponents a la seva Depressió Central. Així, tot el recorregut transitarà entre afloraments dels materials terciaris (de l'Eocè i de l'Oligocè) i quaternaris que reblen aquesta depressió.

Per altra banda, la totalitat del recorregut transitarà per la comarca de l'Anoia, integrant de la Catalunya Central, de principi a fi, des de Sant Genís (del terme de Jorba) fins arribar a la Panadella (que forma part del municipi de Montmaneu). 


\section{Objectius fonamentals}

Els objectius fonamentals que es pretenen aconseguir en aquest itinerari, es poden concretar en els següents aspectes generals:

1. Observació i descripció dels materials terciaris (exclusivament del Paleogen, i més concretament de l'Eocè i de I'Oligocè) de la Depressió Geològica de l'Ebre (i més exactament de la seva Depressió Central). Així, el recorregut de l'itinerari discorrerà entre els afloraments de la Formació Tossa (de I'Eocè), els del Complex Lacustre d'Anoia (amb la Formació Artés, del trànsit de l'Eocè a l'Oligocè) i els del Complex Lacustre de la Segarra (amb les calcàries de la Panadella, ja de l'Oligocè). Tots aquests terrenys constitueixen el subsòl dels diferents sectors, per entre els quals discorre el present itinerari. En part, es realitzarà un tall dels més profunds als més superiors.

2. Observació de les estructures locals de la Depressió Geològica de l’Ebre, al Ilarg del recorregut de l'itinerari; tot i això, no cal oblidar que el recorregut transitarà per una de les zones més estables de la depressió, alterada solament per alguns plecs relacionats amb els nivells de guixos.

3. Observació i reconeixement de les mineralitzacions evaporítiques guixoses situades pels voltants d'Igualada (els guixos d'Òdena de la Formació Tossa) i de Clariana (per on es veuran els guixos intercalats de la Formació Artés, els guixos de clariana)

4. Observació de les explotacions relacionades amb els materials anteriors, com les següents, d'acord amb el sentit de la marxa de l'itinerari.

4A) Les explotacions de les calcolutites roges de la Formació Artés, que veurem al principi del recorregut, a Sant Genís.

4B) Les explotacions dels materials guixosos, que trobarem a diversos indrets de Clariana, entre els materials de la Formació Artés.

4C) de les explotacions dels materials carbonatats de la Panadella-Carbassí, (dintre de la comarca d'Anoia), relacionades sobre els nivells de les calcàries de la Panadella de la Formació Tàrrega.

5. En tots els casos, a les explotacions anteriors, s'observaran les restauracions efectuades en elles, si s'escau.

6. S'observaran, al llarg de tot el recorregut, els diferents elements relacionats amb el Patrimoni Geològic i Miner- 


\section{Antecedents}

Pel que fa al recorregut del present itinerari, existeixen diversos antecedents bibliogràfics parcials. Tot i així, no hi ha cap antecedent general, relatiu als trams centrals del recorregut. Entre els antecedents parcials, farem esment dels següents: Mata-Perelló (1996, 1997, 1999, 2000, 2001, 2005 i 2012).

Pel que fa a la descripció de les mineralitzacions, seguirem fent esment d'alguns altres treballs nostres: Mata-Perelló (1990 i 1991); el primer relatiu a la comarca d'Anoia, el segon al conjunt de les mineralitzacions catalanes.

I, finalment, pel que fa a l'estructura geològica de la zona per la qual discorre l'itinerari, farem esment dels treballs de: Guimerà et altri (1982) i de RIBA et altri (1976).

Tots aquests treballs referenciats, i d'altres, figuren esmentats per ordre alfabètic a l'apartat dedicat a la BIBLIOGRAFIA.

\section{Recorregut de l'itinerari}

El recorregut de l'itinerari discorrerà íntegrament per la comarca de l'Anoia, des de principi a fi. Així, s'iniciarà al poblet de Sant Genís, situat sobre la carretera nacional N - IIA, per on es farà la primera aturada.

Tot seguit, el recorregut es dirigirà cap a llevant, per tal d'arribar fins prop d'Igualada (la capital comarcal), seguint la carretera esmentada anteriorment, després la carretera local B - 222 i finalment la carretera autonòmica C - 241c. En arribar al Polígon de la Plana de Roxella d'Igualada, caldrà fer una nova aturada.

Posteriorment, caldrà retornar fins trobar la cruïlla de la ruta que se'n va cap a Santa Coloma de Queralt, seguint sempre la carretera C - 241c. Més endavant, prop del seu Km 4, es trobarà el trencall d'on eix la carretera local BV - 2212 (la qual es dirigeix cap a Clariana). En aquest recorregut es realitzaran diverses aturades abans d'arribar al poble cap on va la carretera.

Posteriorment, des de Clariana, el recorregut es dirigirà cap al poble d'Argençola, seguint ara el recorregut per una pista forestal en molt bon estat. En aquest tram es farà una nova aturada i una altra en arribar al poble.

Finalment, el recorregut es dirigirà cap el poble de Carbassí, seguint una pista en bon estat. Posteriorment, el trajecte s'adreçarà cap a la Panadella, per la carretera local B - 2234. En aquest darrer tram es farà una nova aturada. 


\section{Advertiments previs}

Com en altres recorreguts de RECERCA GEOLÒGICA I MINERALÒGICA... si es disposa del temps suficient, poden efectuar-se passant per totes les parades i filloles. En cas contrari, recomanem prescindir de les anomenades PARADES - CONDICIONALS.

També cal tenir en conte que part del recorregut, tant a l'inici de l'itinerari, com als seus darrers trams, es realitzarà per camins de terra, per la qual cosa caldrà prendre les degudes precaucions. En aquest recorregut hi haurà un tram d'uns $5 \mathrm{Km}$ per una pista en bon estat.

Cal tenir, com sempre, una cura molt especial de respecte a la natura, al llarg de tot el recorregut de l'itinerari, i també fora d'ell.

\section{Descripció de l'itinerari}

Com de costum, estructurarem el recorregut de I'itinerari en una sèrie de PARADES, que anirem veient. En cadascuna d'aquestes aturades farem un breu comentari (geològic 0 mineralògic, segons s'escaigui). En cada cas indicarem, entre parèntesi, el full topogràfic on es troba l'aturada.

En aquest cas, el recorregut de l'itinerari s'inclourà dintre dels següents fulls, del "Mapa Topográfico Nacional", realitzats a I'escala 1:50.000 per I'"I.G.C. de España": 390 (dit de Cervera) i 391 (o d'Igualada). Tanmateix, si s'escau, es pot utilitzar el Mapa Topogràfic Comarcal d'Anoia, editat per I'Institut Cartogràfic de Catalunya.

Així doncs, la relació de les aturades, que composen el recorregut d'aquest itinerari és la següent.

\subsection{Parada 1. EXPLOTACIONS DE CALCOLUTITES DE SANT GENÍS, (Sant Genís, terme municipal de Jorba, comarca de l'Anoia). (Full 391).}

Tot i que probablement el recorregut s'haurà iniciat a Jorba, ens cal anar cap a les immediacions de Sant Genís, utilitzant I'antiga carretera nacional, I'actual N - IIA. En arribar a la parada de l'autobús, prop del bar Xaloc, farem la primera aturada, després de recórrer uns 2 $\mathrm{Km}$.

En aquest recorregut inicial, haurem trobat afloraments dels materials rogencs de la Formació Artés, amb nivells de gresos i de calcolutites continentals de tonalitats rogenques. Cal dir que aquests materials, a l'indret de l'aturada, tenen un fort component argilós, fet pel qual han estat explotats com a matèria prima per a plantes industrials dedicades a la fabricació de ceràmica. Tot i així, en aquests moments (gener del 2014) es troba tot aturat: I'explotació i la fàbrica.

Així, en aquest indret farem l'aturada, a una antiga explotació; tot i que cal l'autorització per entrar dintre de l'explotació; malgrat això i per aquesta raó, ens aturarem fora. De qualsevol forma, en aquest indret de l'entrada a l'explotació, es pot gaudir d'una bona observació dels materials rogencs de la Formació Artés. (fotografia 1). 


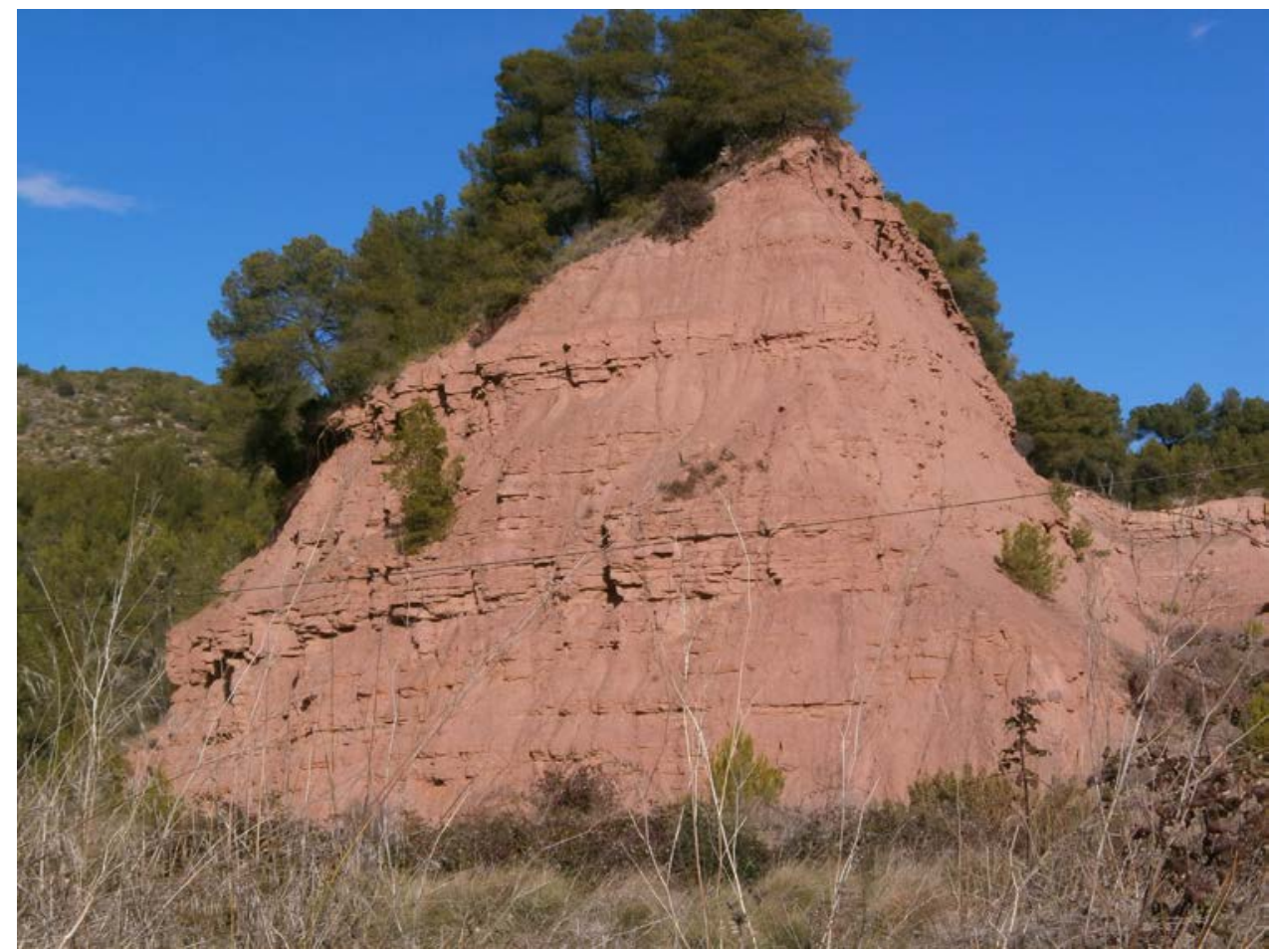

Fotografia 1. Aspecte dels materials rogencs de la Formació Artés. Explotació de Sant Genís

Finalment, cal dir que les tonalitats rogenques d'aquests materials, són conseqüència de la presencia d'HEMATITES entre els materials calcolutitics. Aquest mineral els hi dona la coloració. Al mateix temps ens indica que estem en un ambient oxidant, ja que el $\mathrm{Fe}$ es presenta amb la seva valència 3; és a dir: ens trobem dintre d'un ambient continental.

\subsection{Parada 2. POLÍGON INDUSTRIAL DE LA PLANA DE ROXALLA, (terme municipal d'Igualada, comarca de l'Anoia). (Full 391).}

Després de realitzar la parada anterior, ens cal continuar per la carretera $\mathrm{N}$ - IIA, anant cap a llevant. Així, ens anirem apropant a la població d’Igualada. Poc abans d'arribar-hi i de passar a I'altra banda de l'autovia A - 2, ens trobarem una cruillla, des d'on parteix la carretera local B 222, per la qual continuarem cap a Igualada. Poc després de sobrepassar l'IES, trobarem una altra cruïlla, amb la carretera autonòmica C - 241c. Ens caldrà agafar aquesta carretera, per tal de fer una fillola, anant ara cap al Polígon Industrial la Plana de la Roxalla. Trobarem el trencall a poc menys de $1 \mathrm{Km}$ de la cruïlla, per l'esquerra de la carretera. En entrar-hi, ens caldrà anar cap a munt, arribant al Carrer de Pere Bosch i Soldevila, per on farem una nova aturada, a uns $4 \mathrm{Km}$ de la parada anterior.

En aquest recorregut, inicialment haurem trobat els materials rogencs de la Formació Artés, que hem vist a l'aturada anterior. Tot i així, poc a poc haurem descendit dintre de la sèrie estratigràfica i haurem començat a trobar uns nivells clars, blanquinosos. Efectivament, haurem vist trams de calcolutites guixoses de la Formació Tossa. 
Precisament, aquests són els materials que estem veient en aquests moments, a l'indret de la present aturada. Així, ara es fan palesos uns nivells de guixos (que corresponen als Guixos d'Òdena) els quals formen part de l'esmentada Formació Tossa. (fotografia 2)..

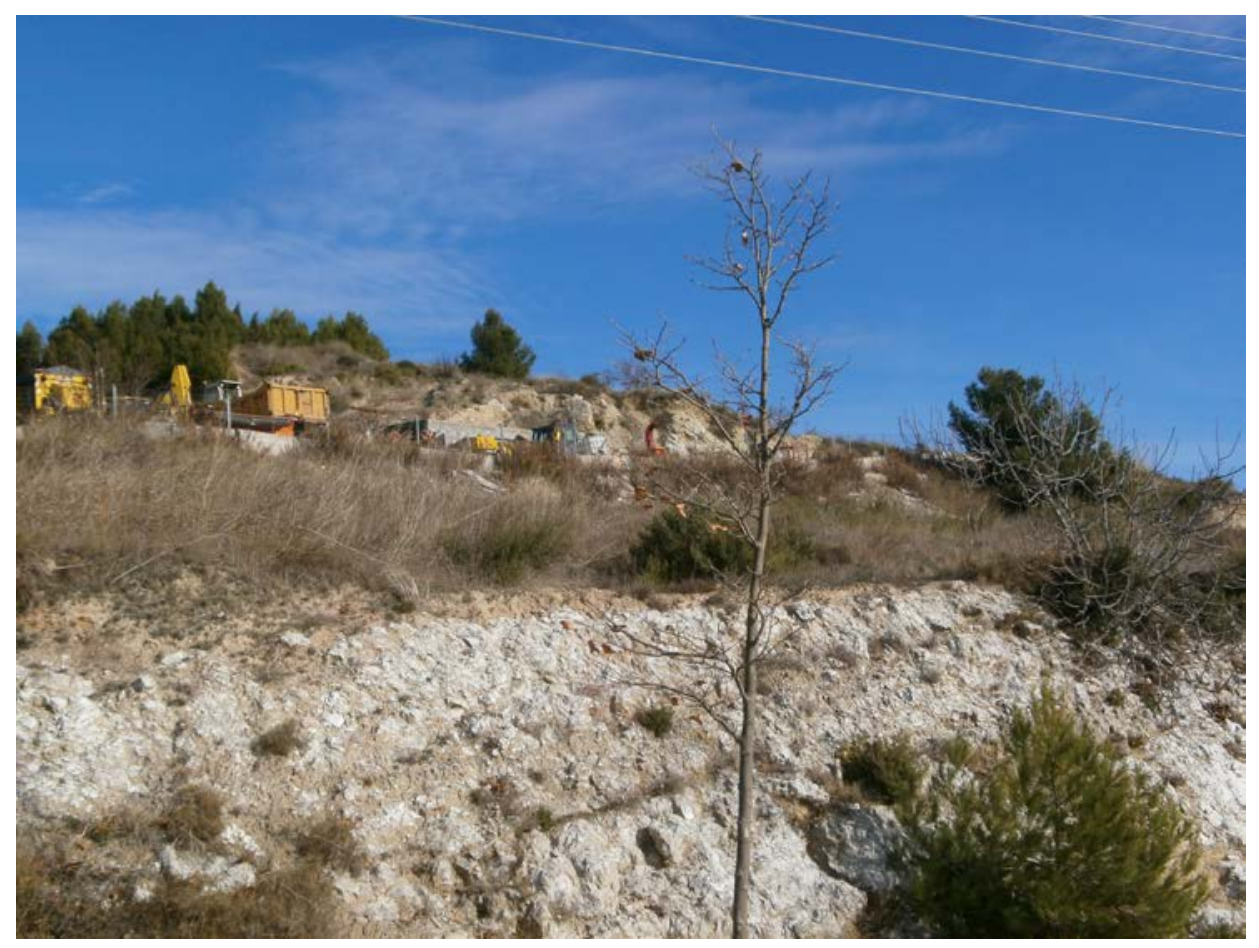

Fotografia 2. Aflorament dels Guixos d’Òdena (Formació Tossa), al Polígon Industrial d’Igualada

Finalment, cal dir que aquests materials han estat explotats a diferents indrets, tant com més amunt d'aquest mateix polígon, com a l'altre polígon industrial situat entre Igualada i Òdena.

\subsection{Parada 3 - CONDICIONAL. TRAM INICIAL DE LA CARRETERA LOCAL A SAIÓ, BV - 2233, (Saió, terme municipal de Santa Margarida de Montbui, comarca de l'Anoia). (Full 391)}

Després de fer la parada anterior, cal retornar cap a la rotonda des d'on surt la carretera autonòmica C - 241c, en el seu sentit cap a Santa Coloma de Queralt. En trobar-la, ens caldrà agafar-la. A uns $2 \mathrm{Km}$ de la rotonda, trobarem un trencall des d'on surt la carretera local BV 2233, que es dirigeix cap al llogarret de Saió. Ens caldrà agafar-la per tal de fer una fillola. En arribar al pont sobre el Barranc de Tous, podem fer una nova aturada. O millor en arribar al Km 1, en front de Saió. Així, des de la parada anterior, haurem recorregut uns $4 \mathrm{Km}$, més u menys.

En aquest recorregut, haurem descendit més en la sèrie estratigràfica. Així, ara s'han fet palesos uns nivells de calcolutites grisenques (o gris - blavoses), que pertanyen a la Formació Igualada, situada sota de la Formació Tossa, que hem vist al llarg d'aquest recorregut. (fotografia 3). 


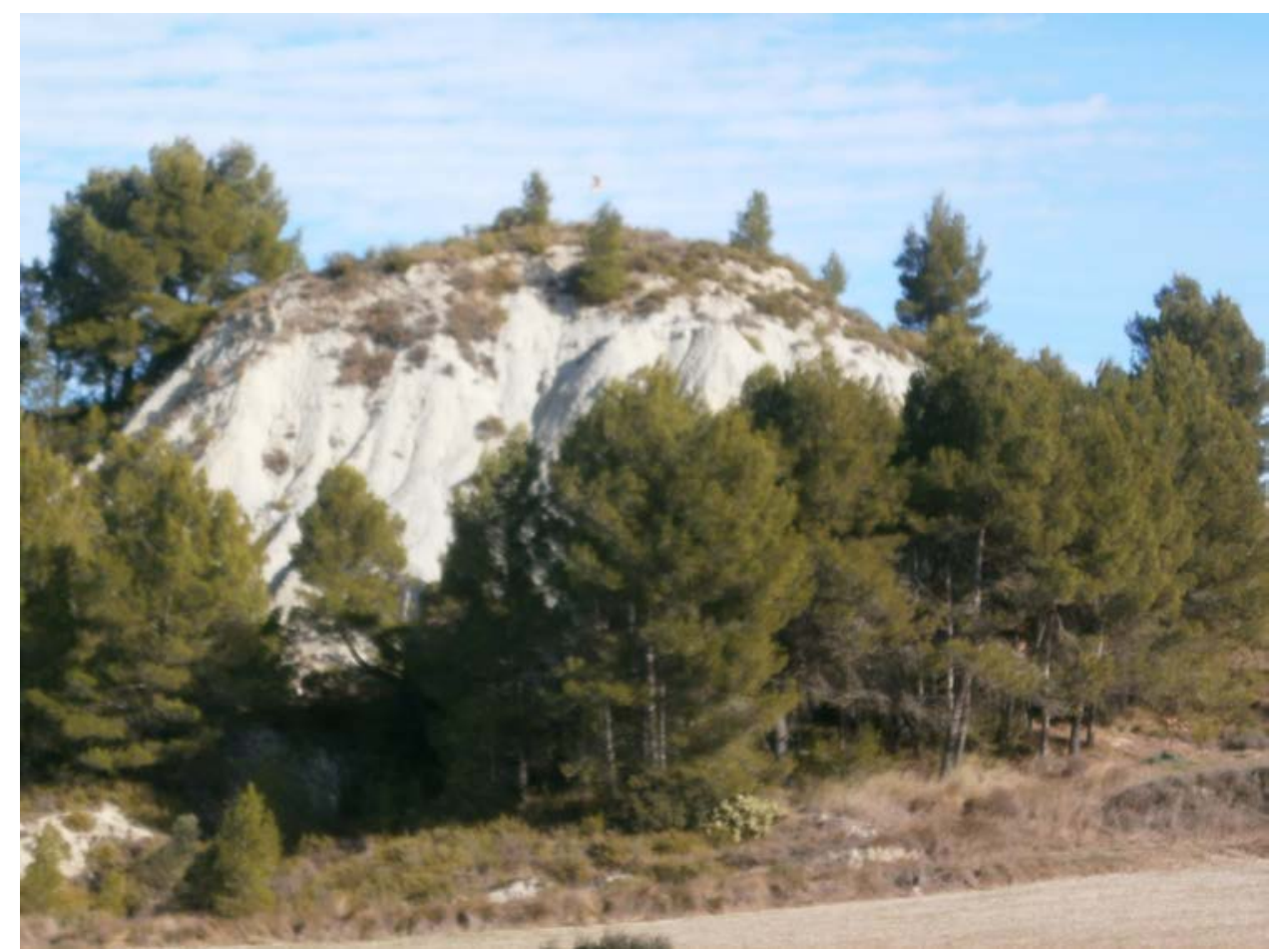

Fotografia 3. Aflorament de les calcolutites grises (gris - blavoses) de la Formació Igualada, a Saió

Finalment, cal dir que a diferència de les calcolutites rogenques que hem vist a la PARADA 1, aquestes d'ara són d'origen marí. Per aquesta raó no hi ha I'HEMATITES que tenyia les primeres.

Efectivament ara el Fe no es troba oxidat sinó reduït; així no es presenta amb la seva valència 3 , sinó amb la seva valència 2; així, ni forma I'HEMATITES ni tampoc la GOETHITA, que ens hagués donat una tonalitat groguenca. En qualsevol cas, ara són grisencs.

\subsection{Parada 4. EXPLOTACIONS DE GUIX DE LES IMMEDIACIONS DEL CASTELL DE CLARIANA, (Clariana, terme municipal d'Argençola, comarca de l'Anoia). (Full 391).}

Després de realitzar la parada anterior, cal retrocedir fins a la carretera autonòmica $C$ - 241c. En trobar-la, continuarem cap a ponent, cap a Santa Coloma de Queralt. Tot i així, en arribar a les immediacions del seu $\mathrm{Km} 4$ ( $i$ en sobrepassar-lo lleugerament), trobarem el trencall d'on surt la carretera local BV - 2212, que haurem d'agafar. Més endavant, en arribar a les immediacions del seu Km 4, prop de les runes del Castell de Clariana, trobarem una pista per I'esquera. En agafar-la i recórrer uns 100 metres, arribarem a la bora d'unes antigues explotacions de guix. Aquí farem una nova aturada, a uns $7 \mathrm{Km}$ de darrera efectuada.

En aquest recorregut, hem anat ascendint en la sèrie estratigràfica. Així, primer haurem vist les calcolutites grises de la Formació Igualada (a la parada anterior). Per sobre haurem trobat els nivells de calcolutites guixoses de la Formació Tossa (entre el pont i la carretera). En arribar a la ruta $C-241 c$, haurem començat a trobar els nivells de calcolutites rogenques de la Formació Artés (que ja havíem vist a la PARADA 1). Ara, en bona part del recorregut per la carretera BV - 2212, haurem vist aquests materials. Tot i així, prop d'on ara som, haurem trobat uns nivells 
grisencs i tanmateix uns nivells de guixos; es tracta dels guixos de Clariana (els quals es situen dintre de la Formació Artés).

I, precisament, en aquest indret aflorem els darrers materials acabats d'esmentar. Aquí, a l'esquerra del camí hi ha unes antigues explotacions, d'on s'extreien aquests guixos. A I'actualitat, aquestes explotacions es troben totalment aturades y sense haver efectuat cap restauració ambiental. (fotografia 4).

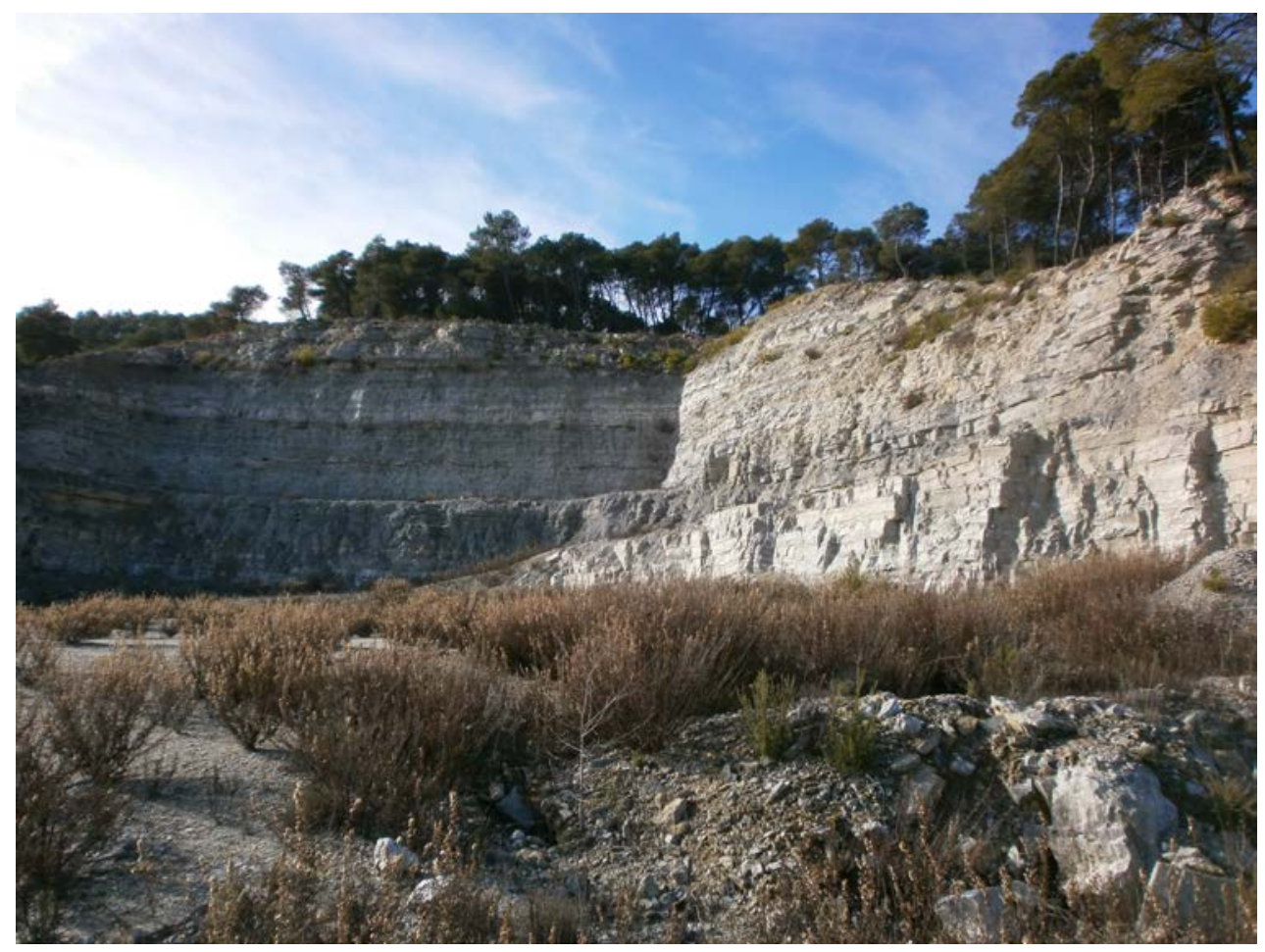

Fotografia 4. Explotacions dels guixos de Clariana (Formació Artés), prop del Castell de Clariana

\subsection{Parada 5. GUIXERA I FORNS DE GUIX, DE LES IMMEDIACIONS DEL CASTELL DE CLARIANA, (Clariana, terme municipal d'Argençola, comarca de l'Anoia). (Full 391).}

Després d'efectuar la parada anterior, cal retornar cap a la carretera local BV - 2212, per tal d'efectuat un curtíssim recorregut (de menys de 50 metres). Així ara trobarem un camí per la dreta, que ens conduirà cap a una antiga guixera (fàbrica de guix), situada a menys de 150 metres de la carretera. Aquí farem una nova aturada, a menys de $0^{\prime} 4 \mathrm{Km}$ de la parada anterior.

En aquest curt desplaçament, haurem continuat trobant els mateixos materials que hem esmentat a la parada anterior. I aquests són també els que es troben al costat de l'antiga fàbrica de guix.

En aquest indret es tractaven part dels materials guixosos explotats per les proximitats. Efectivament, es tracta d'un edifici industrial força interessant, que poc a poc s'està degradant. Efectivament, a la part baixa de la guixera es fan palesos uns antics forns. (fotografia 5). 


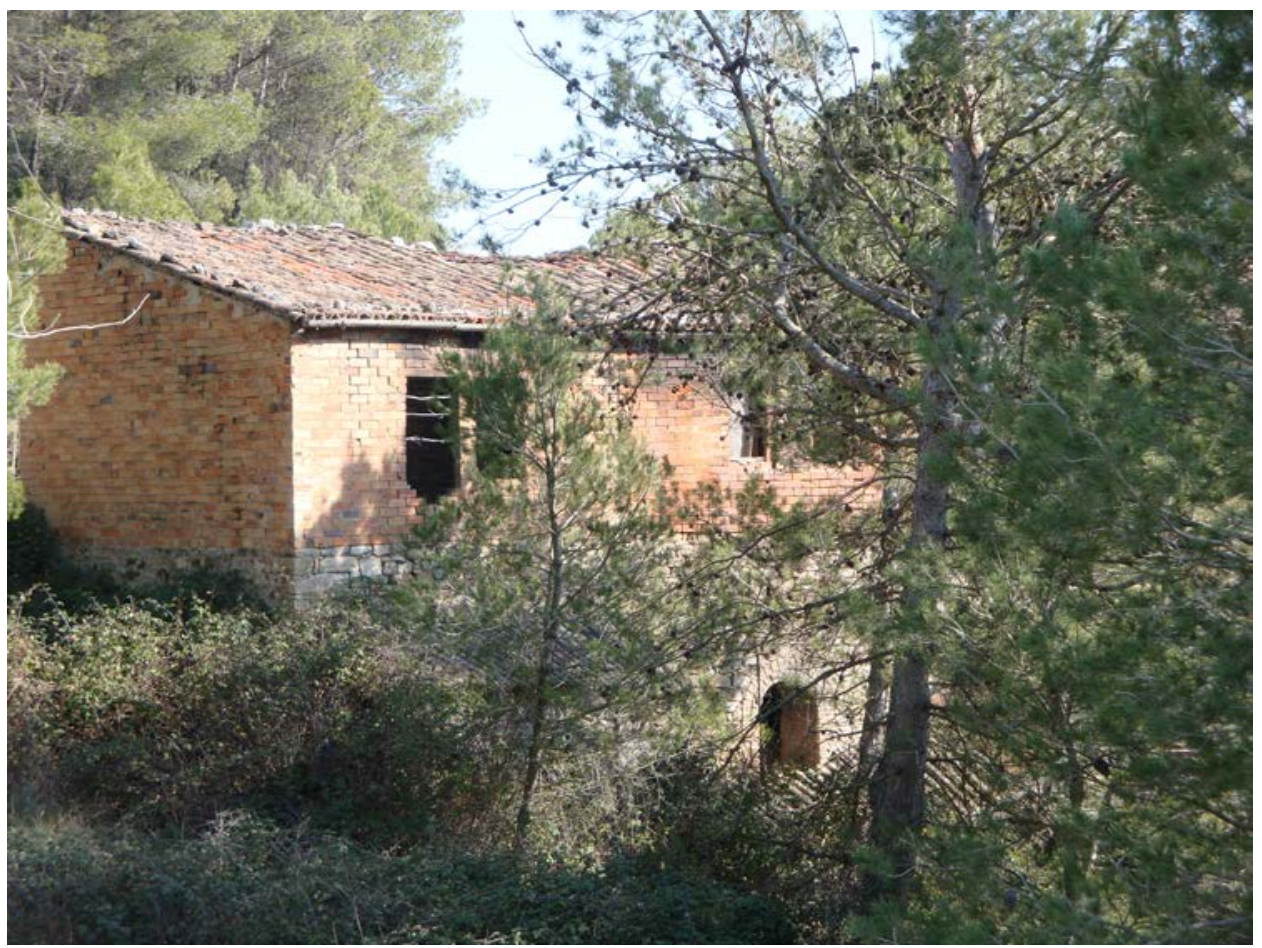

Fotografia 5. Aspecte general de la guixera de les immediacions del Castell de Clariana.

A la part baixa es fan palesos uns Forns de Guix

Tot i el lamentable estat de la guixera, forma part del Patrimoni Miner de la comarca d'Anoia i caldria vetllar per la seva conservació.

Finalment, cal dir que prop de l'edifici anterior, existeixen uns antics i rudimentaris Forns de Guix. Es troben situat al seu llevant a poc menys de 200 metres, tot i que el conjunt està força cobert de vegetació, obstaculitzant el seu reconeixement.

\subsection{Parada 6 - CONDICIONAL. GUIXERA DE JORBA, (terme municipal de Jorba, comarca de l'Anoia). (Full 391)}

Després de fer la parada anterior, cal retornar de nou a la carretera local BV - 2212, per tal de continuar cap el proper poble de Clariana. Si s'escau, en arribar-hi, podem fer una fillola, anant pel camí que es dirigeix cap al poble de Jorba i cap a la N - II. Per aquest camí, arribarem a una antiga explotació de guixos. Aquí. podem fer una nova aturada, a uns $4 \mathrm{Km}$ del poble i a uns 6 de la parada anterior.

En aquest recorregut, hem continuat trobant els materials esmentats a les dues parades anteriors. Aquests són també els materials que es troben a l'indret de la present aturada. Dintre ja del terme de Jorba.

En aquest recorregut, haurem trobat els materials ja esmentats anteriorment de la Formació Artés. Entre aquests nivells rogencs es fan cada vegada més palesos uns trams de guixos (els Guixos de Clariana), que aquí són explotats. Tot i així, per entrar a la Guixera, cal la oportuna autorització. També cal dir que a I'actualitat I'antiga explotació és utilitzada com abocador. (fotografia 6). 


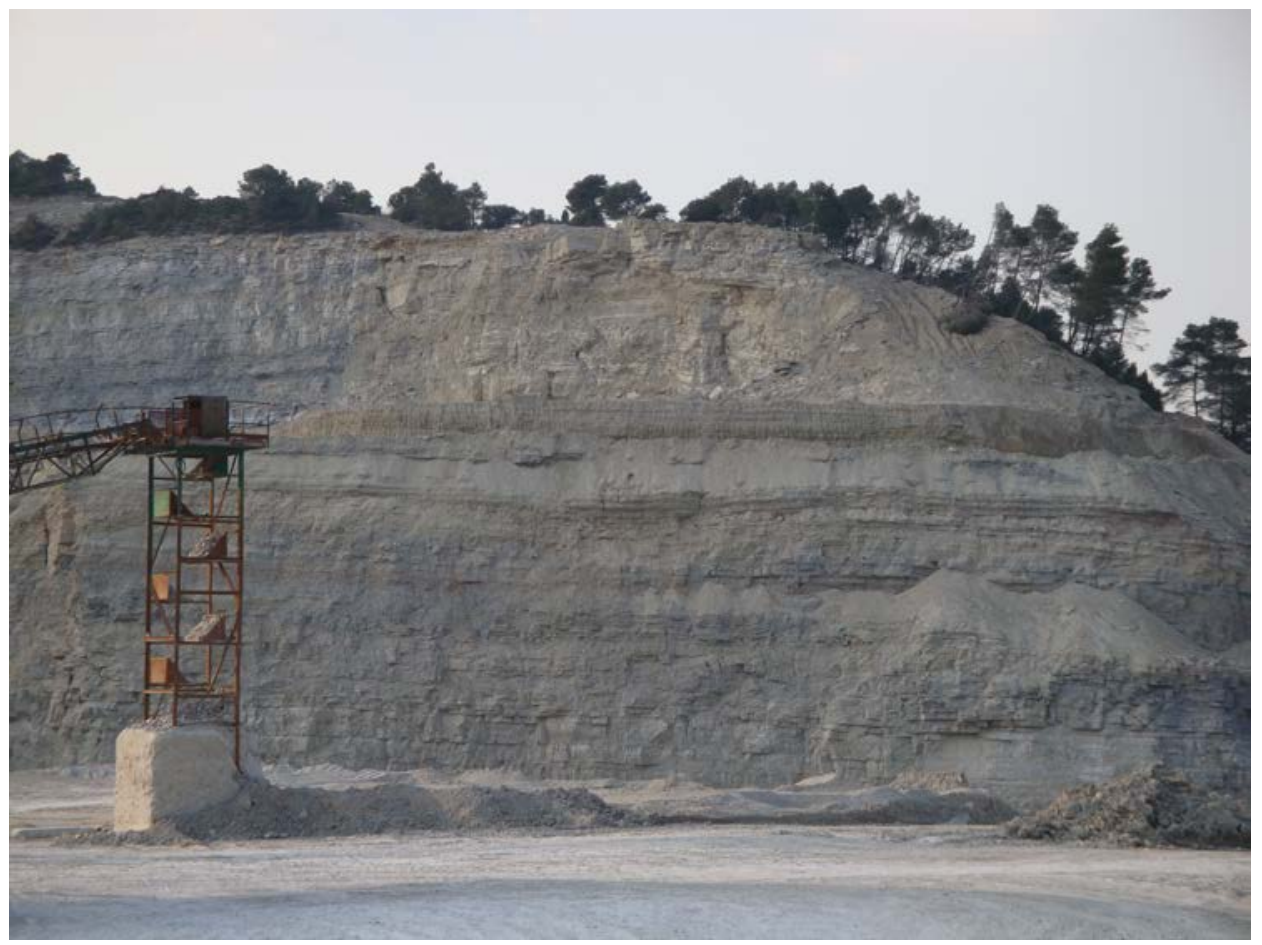

Fotografia 6. Un aspecte de I’antiga explotació. Es poden veure els guixos de Clariana.

Pedrera de Guix de Jorba

A la guixera, actualment abandonada, es poden veure clarament els nivells de guixos explotats. Entre els, es fan clarament palès el GUIX LAMINAR, molt ostentós. Es tracta sempre de guixos secundaris. Tanmateix i més rarament, es poden trobar mostres de GUIX FIBRÓS, però el més abundant és el GUIX MASSIU.

Finalment, cal dir que la guixera ja s'havia fet palesa, des de lluny, en anar de la parada anterior cap el poble de Clariana.

\subsection{Parada 7 - CONDICIONAL. PISTA DE CLARIANA A ARGENÇOLA, (Clariana, terme municipal d'Argençola, comarca de I’Anoia). (Full 391)}

Després de fer la parada anterior, cal retornar cap el poble de Clariana. Un cop aquí, caldrà agafar la pista que condueix cap Argençola, la capçalera municipal. Poc després d'agafar-la, a menys de $1^{\prime} 5 \mathrm{Km}$ de Clariana, podem fer una nova aturada, a uns $5^{\prime} 5 \mathrm{Km}$ de la parada anterior.

En aquest recorregut, haurem trobat els materials anteriors. Així, haurem vist els materials blanquinosos i també els rogencs típics de la Formació Artés, al llarg de tot el recorregut.

En aquest indret és fa més o menys palesa una falla a la bora del camí. De fet, el que es veu és una possible bretxa. (fotografia 7). 


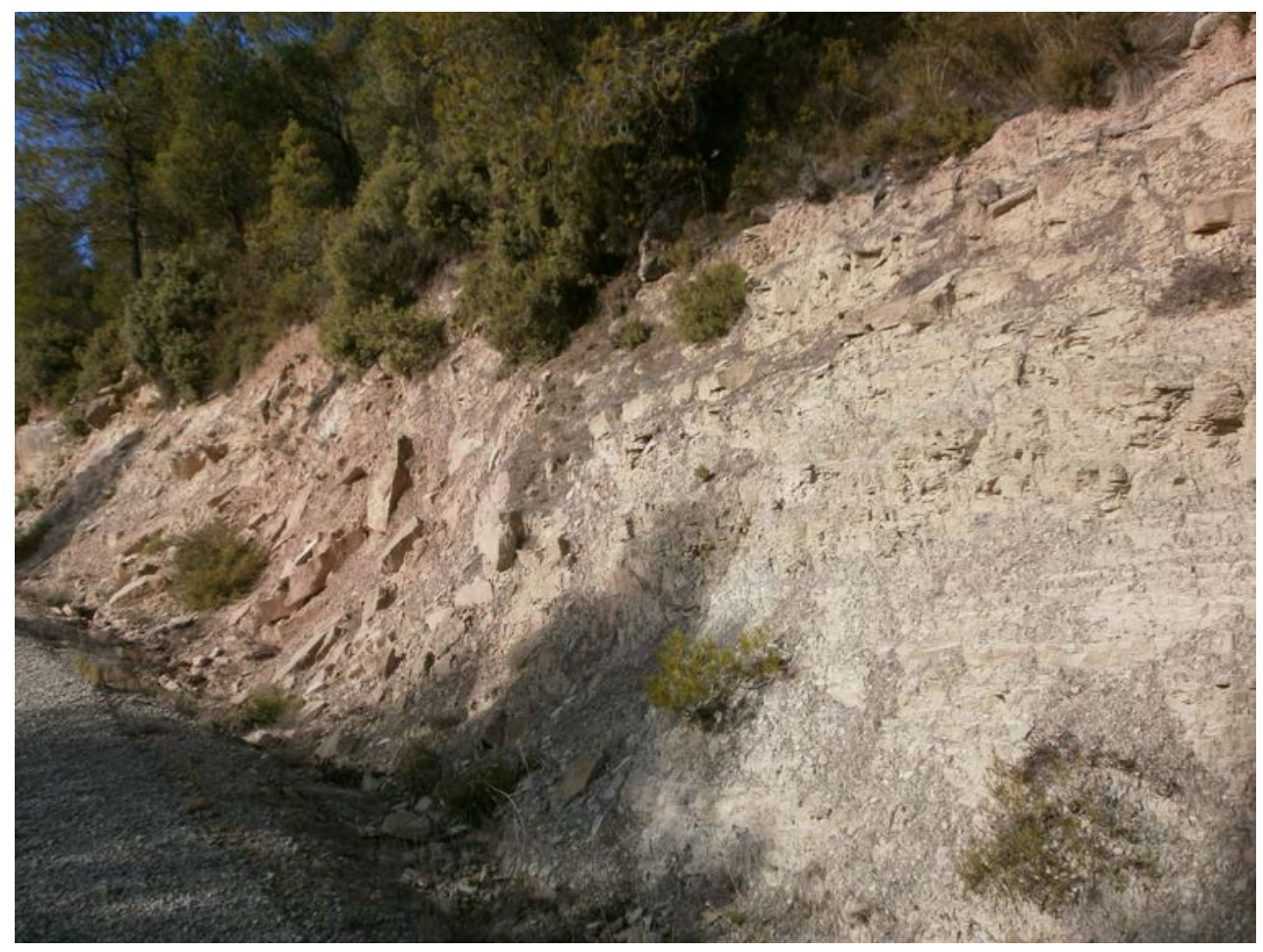

Fotografia 7. Bretxa i possible fractura entre els materials de la Formació Artés. Camí de Clariana a Argençola

\subsection{Parada 8. INICI DE LA CARRETERA D’ARGENÇOLA A AGUILÓ, (terme municipal d'Argençola, comarca d'Anoia). (Full 390).}

Després d'efectuar l'anterior aturada, cal continuar pel camí que es dirigeix cap el proper poble d'Argençola, a on arribarem després de recórrer uns $4 \mathrm{Km}$ més. En arribar-hi, cal rodejar el poble entornat, per tal d'arribar a la carretereta que surt per ponent, cap a Aguiló i cap a Santa Coloma de Queralt. Aquí, farem una nova aturada, a uns $5 \mathrm{Km}$ de la parada anterior.

En aquest recorregut, hem anat ascendint a la sèrie estratigràfica, arribant ara al denominat Complex Lacustre de la Segarra. Així, ara es fan palesos uns nivells carbonatats, que pertanyen als trams alts de les denominades Calcàries d'Albarells, de la Formació Tàrrega. (fotografia 8). 


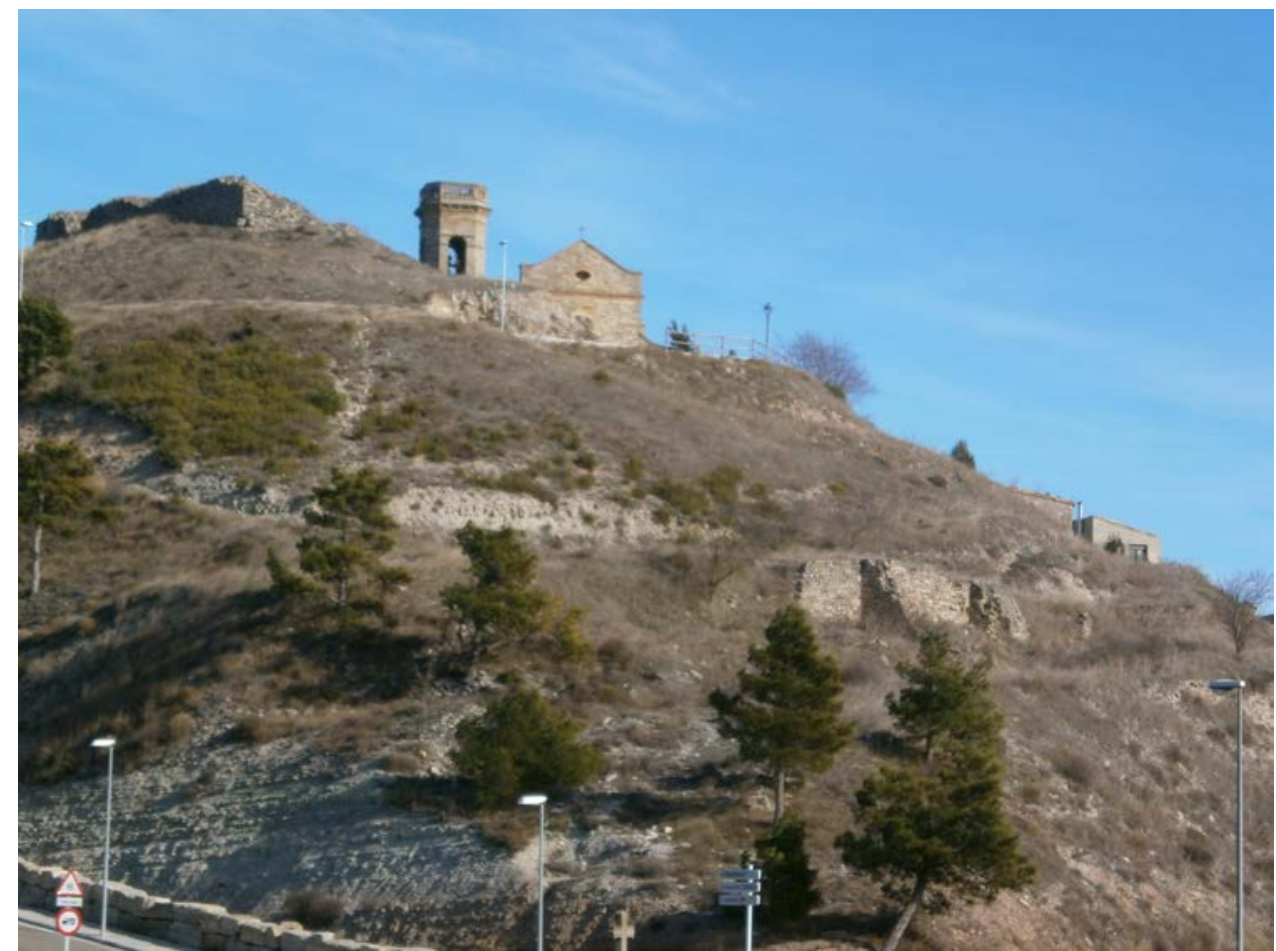

Fotografia 8. El poble d'Argençola, situat sobre d'un turó, per on afloren els nivells carbonatats de les calcàries d'Albarells (Formació Tàrrega)

Per altra banda, des d'aquest indret, mirant cap el Nord, es pot veure el poble de Carbassí, situat sobre aquestes mateixes calcàries.

\subsection{Parada 9. EXPLOTACIONS DE CALCÀRIES DE CARBASÍ - LA PANADELLA, (la Panadella, terme de Montmaneu, comarca d'Anoia, subcomarca de la Segarra Anoienca). (Full 390).}

Un cop efectuada la parada anterior, cal anar cap el proper poble de Carbassí . Així, haurem de baixar cap al Torrent del Molí de les Vinyes, per tal de pujar després cap el poble on anem en primer terme. En arribar-hi, ens caldrà seguir per la carretera local BV - 2234, la qual es dirigeix cap a la Panadella. Entre mig dels dos pobles començarem a trobar unes antigues explotacions de calcàries. Aquí farem una nova aturada, a uns $5 \mathrm{Km}$ del poble d'Argençola, aproximadament.

En aquest recorregut, hem trobat els materials esmentats a l'aturada anterior. Així, en passar per Carbassí, haurem vist de les calcàries d'Albarells. Més endavant, en el tram cap a la Panadella, trobarem uns nivells sorrencs i calcolutítics, i finalment, dalt de tot, les anomenades calcàries de Montmaneu - la Panadella.

Al respecte, cal recordar que tots aquests materials formen part de Formació Tàrrega, constitueixen aquí el Sistema lacustre de la Segarra. Aquestes calcàries, per canvi lateral de fàcies passen a la Formació Calaf, la qual es troba amplament representada més cap al NE d'un ara ens trobem. Aquests darrers materials són els que es troben al Port de la Panadella, on constitueixen una suau cinglera, una clara "cuesta. Aquesta cinglera constitueix la divisòria 
d'aigües entre la vall del Segre, i la de I'Anoia. Així, per sota de les calcàries, cap al Nord, neixen el riu D'Ondara i el riu Corb, tributaris del Segre. Mentre que cap al Sud ho fa el riu Anoia, tributari del Llobregat.

Per d'altra banda, en aquest lloc, on fem la present aturada, hi ha una important explotació a "cel obert" dels nivells carbonatats dels quals hem acabat de parlar. Aquestes calcàries, en bona part s'utilitzen $\mathrm{cm}$ a àrids. (fotografia 9).

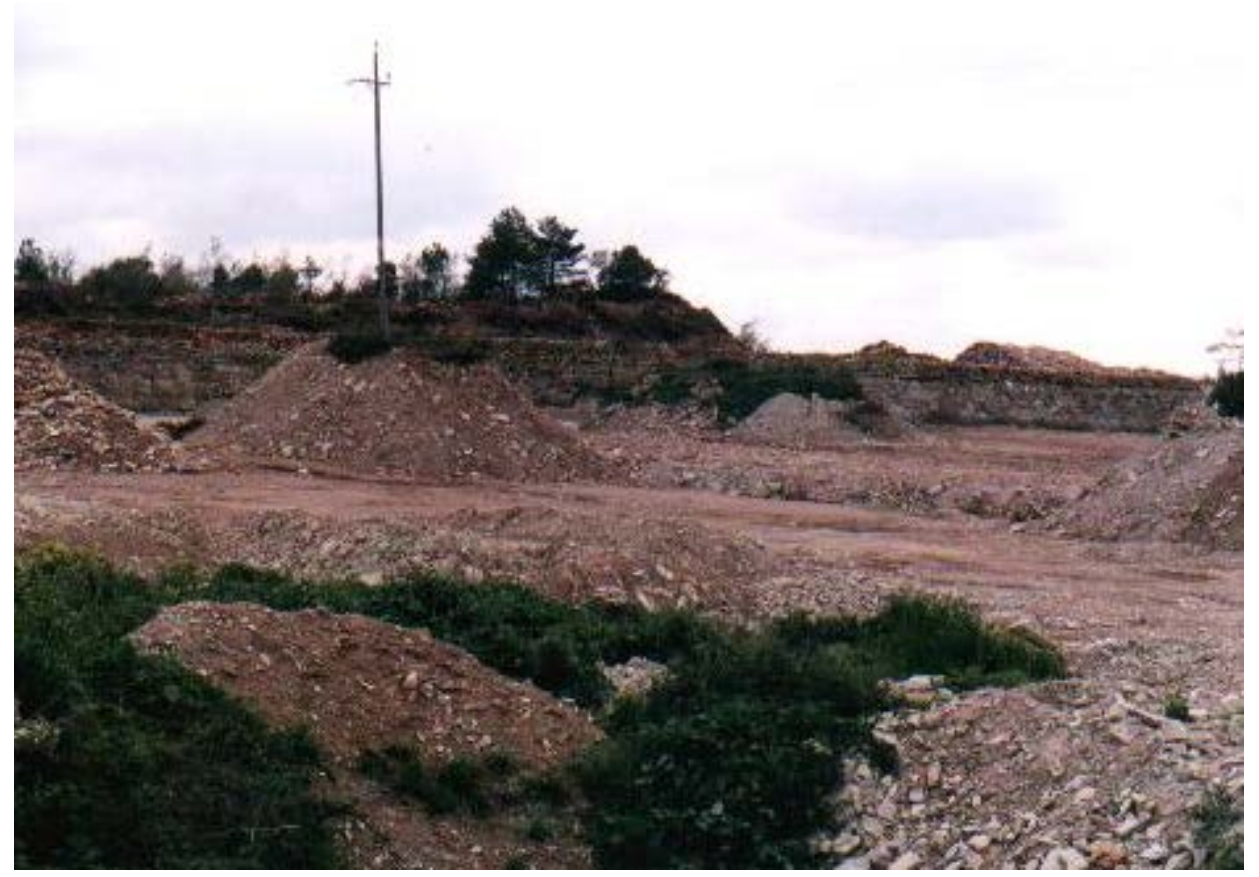

Fotografia 9. Un aspecte de l'explotació de les calcàries de la Panadella. Pedrera de Carbassí - la Panadella al juliol de l'any 2000.

En aquest indret finalitza el recorregut de l'itinerari. 


\section{Bibliografia}

GUIMERÀ, J. et altri (1992).- Geologia (II), Història Natural dels Països Catalans, Vol.2, 547 pag. Enciclopèdia Catalana, S.A. Barcelona.

MATA-PERELLÓ, J.M. (1990).- Inventari Mineralògic de la comarca d'Anoia. Revista Xaragall, $\mathrm{n}^{\circ} 24,40$ pag. Manresa.

MATA-PERELLÓ, J.M. (1991).- Els Minerals de Catalunya. Arxius de la Secció de Ciències, t. XCIII, 442 pag. Institut d'Estudis Catalans. Barcelona.

MATA-PERELLÓ, J.M. (1996).- Recerca geològica i mineralògica per les comarques d'Anoia, Segarra, Conca de Barberà, Segarra i Urgell: des de Jorba a Preixens. Inèdit, 19 pàgines, Manresa.

MATA-PERELLÓ, J.M. (1997).- Recerca geològica i mineralògica per les guixeres de la comarca d'Anoia: des d'Òdena i l'Espelt a Jorba i a Clariana. Inèdit, 11 pag. Manresa.

MATA-PERELLÓ, J.M. (1999).- Recerca geològica i mineralògica per la comarca d'Anoia: des d'Òdena i l'Espelt a Jorba, i des de Clariana i Argençola a Bellmunt i Aguiló. Inèdit, 10 pag. Manresa.

MATA-PERELLÓ, J.M. (2000).- Recerca geològica i de reconeixement dels georrecursos per les pedreres de la comarca d'Anoia: des d'Òdena i l'Espelt a Sant Martí de Tous, i des de Clarianai i Argençola a Carbassí. Algeps, sèrie B, $n^{\circ}$ 172, 11 pag. Manresa.

MATA-PERELLÓ, J. M. (2001).- Recerca geològica i geoambiental per les comarques d'Anoia i de la Segarra: des d'Òdena i l'Espelt cap a Sant Genís i Jorba, i des de Montmaneu a Sant Pere dels Arquells. Inèdit, 8 pàgines. Manresa.

MATA-PERELLÓ, J. M. (2012).- Recorregut de recerca geològica i geoambiental per les comarques del Bages, d'Anoía i de la Segarra: des de Maians i Òdena cap a Jorba, la Panadella i a Sant Pere dels Arquells. Inèdit. 14 pàgines. Manresa.

RIBA, O. et altri (1976).- Geografia Física dels Països Catalans, Edit. Ketres, 254 pàgines. Barcelona. 